UCRL--92732

DE86 003476

THE DESIGN, CONSTRUCTION, AND TESTING OF THE VACUUM VESSEL FOR THE

TANDEM MIRROR FUSION TEST FACILITY

Jerry W. Gerich

This paper was prepared for submittal to the American Vacuum Society, 32nd National Symposium

Houston, Texas, November 19-22, 1985

\title{
November 1985
}

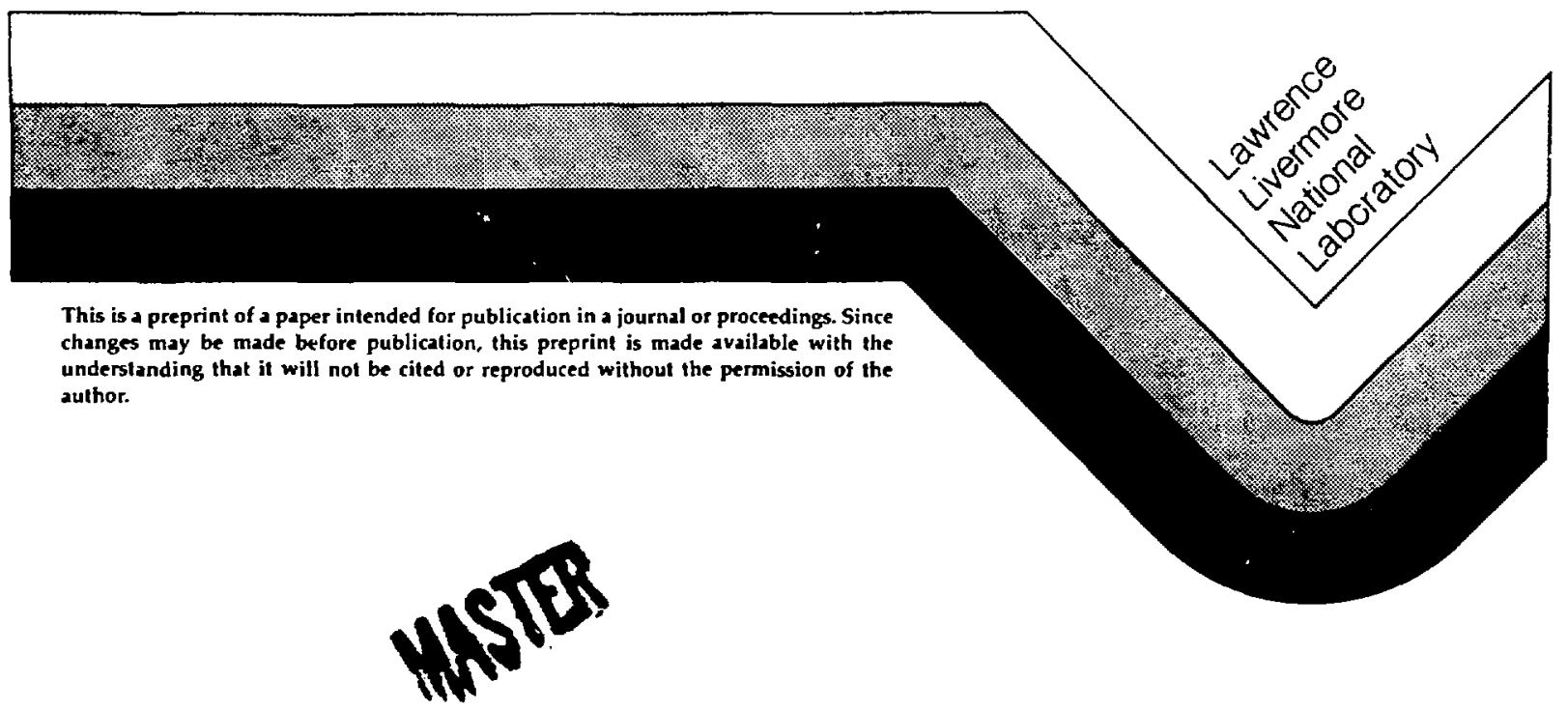


JS1 ThM1

\title{
THE DESIG, CONSTRUCTION, AND TESTING OP THE VACUUH VESSEL \\ FOR THE TANDEM MIRROR FUSION TEST FACILITY
}

\author{
Jerry W. Gerich \\ University of California, Lawrence Livermore National Laboratory \\ P. O. Box $5511, L-538$ \\ Livermore, California 94550 U.S.A. \\ (415) $422-1464$
}

\section{ABSTRACT}

In 1980, the U.S. Department of Energy gave the Lawrence Livertiore National Laboratory approval to design and build a tandem Mirror Fusion Test Facility (MFTF-B) to support the goals of the National Mirror Program. We designed the MFTF-B vacuum vessel both to maintain the required ultrahi-h vacuum environment and to structurally support the 42 superconducting me- nets plus auxiliary internal and external equipment. During our design work, we made extensive use of both simple and complex computer models to arrive at a cost-effective final configuration. As part of this work, we conducted a uni que dynamic analysis to study the interaction of the 32,000-tonne concrete-shielding vault with the 2,850-tonne vacuum vessel system. To maintain a vacuum of $2 \times 10^{-8}$ Torr during the physics experiments inside the vessel, we designed a vacuum pumping system of enormous capacity. The vacuum vessel $\left(4,200 \mathrm{~m}^{3}\right)$ has been fabricated, erected, and acceptance tests have been completed at the Livermore site. The rest of the machine has been assembled, and individual systems have been successfully checked. On October 1, 1985, we began a series of integrated engineering tests to verify the operation of all components as a complete system. 


\section{INTRODUCTION}

\section{A. History}

The first of three versions of the Mirror Fusion Test Facilicy (MFTF) originated in 1977 when the U.S. Department of Energy (DOE) gave Lawrence Livermore National Laboratory (LLNL) approval to design and build a simple, single-cell mirror mach'ne to explore physics scaling laws and to advance the technology of mirror fusion devices. This machine $h \cdot d$ a $1600 \mathrm{~m}^{3}$ vacuum vessel. Suspended inside the vessel were a pair of superconducting C-shaped magnets, called the yin-yang pair. This vessel alsc surported the internal cryopumping system, the external rough- and high-vacuum systern, the neutral beam injectors, and the diagnostic system. This entire, 1000-tonne machine rested on a concrete foundation and was surrounded by a $2-m-t h i c k$ concreteshielding vault.

In 1979, we at LLNL built, and operated the first tandem mirror machine. As a result of our significant achievements with this Tandem Mirror Experiment (TMX), we received DOE approval in 1980 to change the single-cell MFTF to a tandem mirror design, which was the second version of MFTF. This meant dding a center vessel with solenold and transition magnets and also duplicating the original vacuum vessel and yin-yang magnets at the other end of the machine. In addition, auxiliary C-shaped magnets, called A-cells, were placed outboard of the two yin-yang magnets. This change in the configuration required an extension to each of the end vessels: this extension supported the new magnets. We named this new A-cell configuration the Tandem MJrror Fusion Test Facility, or MFTF-B.

The detailed design work on MFTF-B began just as our engineering staff and their subcontractors were finishing the assembiy of the original MFTF. During the first half of fiscal year 1982, we conducted a very successful 
series of engineering tests on the MFTF vacuum vessel, the yin-yang magnets, and the other systems to verify their design parameters. Immediately after thece extencive tests, we disassembled MFTF for reconfiguration to the tandem MFTE-B A-cell design. The new machine incorporated essentially all of the existing hardware, including the vacuum vessel and its foundation.

In 1982, we made one other major change to the vacuum vessel, magnets, and most of the other systems. This physics-initfated modification was undertaken to complement the maln-line approach to mirror-fusion reactors. This third configuration of MFTF was called the MFTF-B Axicell design. It increased the number of major magnets from 22 to 26 and eventually added 16 smaller magnets called trim coils. These changes had a large impact on the vacuum vessel design-every magnet was relocated, causing changes in the loading pattern. Also, the end-vessel extensions were eliminated because the resident A-cell magnets were not needed. All of these design changes required new structural calculations, but, fortunately, fabrication of the tandem vacuum vessel had not begun because we had been anticipating these changes for many months. Figure 1 shows the overall configuration of the MFTF-B Axicell, its major systems, and its location inside the building and concrete shielding vault.

The detailed design, fabrication, and field erection of both the MFTF and the MFTF-B vacuum vessels were awarded to subcontractors through competitive bidding processes. The CVI Corporation of Columbus, Ohio won the contract for MFTF, which included the vacuum vessel; the internal, external, and rough vacuum- pumping systems; and the cryogenic system. The CVI Corporation subcontracted this initial vacuum vessel to the PittsburghDes Moines Corporation (PDM) of Pittsburgh, Pennsylvania. Several years later, after another competitive bidding process, PDM won the contract for the 
MFTF-B vacuum vessel on July 1, 1981. Very close cooperation among the CVI, PDM, and LLNL engineering staffs ensured that all the system requirements were met for these challenging projects.

\section{B. Requirements}

The primary functions ${ }^{1}$ of the MFTF-B vacuum vessel are (1) maintain the vacuum environment created by the pumping system for the plasma experiments; (2) provide the structural support for the superconducting magnets and the other internal and external systems. In addition, the design of the central cell requires a modular construction that allows for reconfiguration of the inboard magnet set without first removing the giant yin-yang magnets.

We chose ASTM A240 Type-304 stainless sleel for the vacuum vessel because it is nonmagnetic, has good fracture coughness and welding properties, is readily available in many standard shapes, and is reasonably priced. Most other parts of the vessel system, such as the support legs and magnet attachment brackets, are also made of the Type-304 stainless steel.

To maintain the required high vacuum, we polished the entire inner surface of the vessel. We also placed most of the stiffening structure on the outside of the vessel, which had the advantage of reducing the interior vessel surface area for ease of cleaning and for lower outgassing during vacuum operations.

The basic size and shape of tice vacuum vessel are determined by the geometry of the superconducting magnet set. We allowed some additional space for cryopanels, neutral beam dumps, plasma end dumps, and worker access, and arrived at a horizontal, central-cell cylinder that is $8 \mathrm{~m}$ in diameter and $20 \mathrm{~m}$ long, capped at each end by horizontal, cylindrical end vessels, $10.6 \mathrm{~m}$ in diameter and $16 \mathrm{~m}$ in length. With the conical sections that join the end 
vessels to the center vessel plus the spherical end domes, the entire assembly measures $58 \mathrm{~m}$ in length and encompasses a high-vacuum volume of $4200 \mathrm{~m}^{3}$ (Fig. 2).

In the central cell region, we met the reconfiguration constraints by designing six removable-vessel modules, each containing two of the solenoid magnets. Originally, these six modules encompassed the entire 20-m length of the center vessel. However, when the machine was reconfigured to the axicell design, we moved the solenoid magnets closer together. Consequently, the center vessel now consists of the six removable modules plus a 4-m-1ong, 8-mdiameter transition cylinder at each end. These cylinders are welded to the conical sections of the end vessels.

\section{Vacuum Pumping System}

The MFTF-B machine requires a vacuum pumping system that can take the vacuum vessel and its contents from atmospheric pressure to a base pressure of $1 \times 10^{-8}$ Torr in less than two days. In addition, after deuterium is injected during physics operations, this equipment must produce a pressure of $2 \times 10^{-8}$ Torr prior to each physics experiment. There are three main components of the pumping system that perform these tasks. ${ }^{2}$ First, the four roughing trains, each consisting of a mechanical pump and two Roots blowers, evacuate the vessel to $1 \times 10^{-2}$ Torr. Second, ten high-vacuum cryopumps that are mounted or the outside of the vacuum vessel bring it to $1 \times 10^{-6}$ Torr. (These pumps can be 1solated from the internal vacuum environment and regenerated.) Third, $1000 \mathrm{~m}^{2}$ of internally mounted liquid-nitrogen-shielded liquid-helium cryopanels are brought on line by introducing the cryogens, thus obtaining the $1 \times 10^{-8} \tau$ r base pressure.

During physics experiments, plasma shots can occur at five-minute intervals, and the deuterium that is injected is actively pumped internally by 
the cryopanels. The most difficult residual gases that we pump are the light ones--helium, hydrogen, and hydrogen-deuteride--all of which are introduced during the 30-s duration of the plasma shots. This pumping is performed by four of the ten high-vacuum pumps that operate at $2.8 \mathrm{k}$, which is below the normal operating temperature of $4.5 \mathrm{~K}$. They are two-stage pumps that cryocondense the hydrogen and hydrogen-deuteride and incorporate an argoninjection, cryosorption system for pumping the helium.

\section{DESIGN OF THE VACUUM VESSEL}

\section{A. Design Process}

Soon after the tandem mirror concept was approved in 1980, LLNL began development of an extensive, three-dimensional, finite element model of the new vacuum vessel. The results from this preliminary model provided the basis for the procurement specification for the vessel, and they also generated interface geometry and rough loading values for other project components, such as the vessel foundation. This stage was completed in early 1981.

Our preliminary design work with the finite element model and an improved version of the SAP! computer code ${ }^{3}$ solidified the general vessel configuration as a thin-walled cylinder for vacuum isolation with substantial external stiffening to handle the additional structural demands. (This is the same design concept as the original MFTF vessel.) At each magnet location, we placed a circumferential or ring stiffener with a "T" cross section. Although the ring stiffener itself had a "T" cross section, when welded to the vacuum vessel skin, the effect was the same as an I-beam cross section. These $r$ ing stiffeners rested on a set of legs fastened to concrete piers under the end vesse's and a steel structure under the center vessel. To carry vessel loads 
in the longitudinal direction, we reinforced the shell with various additional stiffeners along the length of the shell surface.

After PDM joined the vacuum vessel team, our design effort branched intc several parallel efforts, pursuing different objectives. Our LLNL team refined and updated the vessel model to reflect the evolving physics and engineering developments so that we could generate design criteria for both the concrete foundations and the magnet support struts. In this way, we could also verify the PDM design calculations.

The PDM engineering group split into several design teams to provide a detailed design and stress analysis for the entire vessel. One PDM team developed two-dimensional models (in the transverse plane) of the approximately two-dozen ring stiffeners and sized them with the ANSYS computer code. A second team generated a two-dimensional ANSYS beam model of the vessel and its supporting legs (in the vertical longitudinal plane) to study the distribution of loads in the axial direction. Other PDM engineering staff employed hand and computer calculations to determine the thickness of the shell plate to be used in fabricating the thin-wall vacuum cylinder. These calculation methods were also used to analyze local features such as the end domes and support legs.

To meld these design efforts and to account for three-dimensional interactive effects, the PDM analytical group began a finite element model synthesizing the entire vacuum vessel, the magnets, the supporting legs, and the foundations. To permit stress analysis, this detailed model grew to twice the size of the LLNL model and conslsted of over 4600 elements. The initial size and shape of the features in this three-dimensional model came directly from the results of the two-dimensional models and hand calculations. 
Luring our early design effort at LLNL, we had reason to believe that we could substantially reduce the magnitude of the transverse and longitudinal components of earthquake acceleration because of the interactions of the vacuum vessel and its foundation with the soil and the surrounding massive concrete vault. To study this soil-structure-interaction (SSI) effect and to verify the estimate of a $25 \%$ load reduction, which we decided to use as our design basis, LLNL contracted with Structural Mechanics Associates (SMA). They used an existing finite-element model of the vault, the LLNL vessel model, and local soll data to perform a CLASSI computer-code analysis.

To do the response spectrum analysis with the SAP4 code and the LLNL and PDM models, we needed to know or estimate a damping coefficient for this dynamic portion of the calculations. Because we had already built the MFTF vessel and installed the large yin-yang magnet pair inside, we were able to perform a series of dynamic excitation tests and measure the actual decay rate, or structural damping, at many different locations on the vessel." We fourd the average damping coefficient was $5 \%$, considerably higher than the $1 \%$ to $2 \%$ that is regularly used for nuclear power plant design. Thus, the use of this higher damping value produced significantly lower earthquake design loads for the MFTF-B vacuum vessel.

The design process for the MFTF-B vacuum vessel was highly iterative, and the process involved not only the use of the codes and methods just mentioned, but it also took advantage of considerable information and results 
generated by other groups. For an excellent overview of the analysis methodology our project used, see Karpenko and $\mathrm{Ng}$ in Ref. 5.

\section{B. The Vessel Loading Requirements}

To properly perform the magnetic fusion experiments, the vacuum vessel must sustain numerous loading situations, both static and dynamic. The seven static forces ${ }^{6}$ producing these loads on the vessel are defined in the following subsections.

Gravity Load. The gravity load is caused by the $1-\mathrm{B}$ force acting straight downward on the entire mass of the vessel and the components it supports. These masses are the vessel itself (1100 tonnes), the superconducting magnet set (1250 tonnes), and the auxiliary components inside and outside the vessel (500 tonnes).

External Pressure Load. The external pressure load is caused by the standard atmospheric pressure acting on the vessel shell when the vessel is under vacuum, plus an additional $10 \%$ of the atmospheric load to account for magnetic pressure on the shell resulting from the sudden collapse of the magnetic field.

Thermal cooldown Load. The thermal cooldown load is caused by the magnets cooling to $4 \mathrm{~K}$, while the vessel remains at room temperature. Because the magnets are connected to the vessel by a number of support struts on each magnet group, the possibility exists for an over-constrained strut system to generate thermal contraction loads. This happened with the yin-yang system in the original MFTF. However, in MFTF-B, we were able to decrease the seven yin-yang support struts to six, thereby removing all thermal cooldown loads. We always included this load case in our computer analysis, though, to ensure that design changes did not catch us with an over-constrained system. 
Environmental Thermal Load. The environmental thermal load is caused by the variation in the air temperature surrounding the vessel. Because MFTF-B will be enclosed in the 32,000-tonne concrete vault during normal physics operations, we used a thermal excursion of only $5.6^{\circ} \mathrm{C}$ for our calculations. Magnetic Normal Load. The magnetic normal load is caused by large axial forces that are generated by the magnet set during normal operation. These forces are transmitted into the ressel by a series of drag struts. Magnetic Fault Load. The magnetic fault load is caused by additional and, in many cases, much larger axial forces that are generated when one or several magnets switch from superconducting to normal. Numerous fault conditions are possible. We generated a load matrix and then chose the most severe case to use as our design basis for each magnet group.

Magnet Misallgnment Load. The magnet misalignment load is caused by a radial or side force that develops on energized magnets that are not perfectly aligned. The magnitude of these loads is determined by the tolerances that can be obtained during the installation of the entire magnet set. Also, for the MFTF-B Axicell magnet set, the trim colls produce addilional side loads when they are energized.

These static forces make up the seven static load cases in our SAP4 stress analysis. Our procedure is to first calculate every load case separately, so we can study each situation to ensure that the model is behaving properly. Next, we sum the loads alsebraically for each region to obtain the total static component of the load. Then, for several combinations of these static loads, we compare the stresses generated by these loads with the allowable stress for the Type-304 stainless-steel vessel material. Dynamic forces acting on the vacuum vessel are based exelusively on the most severe credible earthquake postulated for Livermore, California, where 
MFTF-B is located. (Livermore is a region with active earthquake faults.) This site-specific spectrum has a zero-period acceleration (ZPA) of $0.25 \mathrm{~g}$ and is applied in the two horizontal directions. The vertical excitation is scaled by two-thirds of the horizontal ZPA.

During 1982, SMA completed their SSI study on the first configuration of MFTF-B (the second design with the A-cell magnets at each end). ${ }^{7}$ on the average, the SMA analysis showed that the total effect of this soil-structureinteraction was to reduce the two horizontal components of the dynamic loads in the vessel to slightly less than $75 \%$ of the values calculated with SAP4. Both LLNL and PDM took advantage of this discovery by lowering response spectrum acceleration input by $25 \%$ in the transverse and longitudinal directions.

The stresses for this dynamic load case were calculated with the SAP4 code, and the results were combined with the appropriate static load cases. We compared these stress values to the stainless-steel allowable stress. A lower safety margin is applied to this earthquake case because of its low probability of occurrence during the machine's ten-year design life.

\section{REDESIGN TO THE AXICELL CORFIGURATION}

\section{A. Axicell Configuration}

As the PDM engineering groups were finishing their design calculations in mid-1982, LLNL decided (with DOE approval) to modify MFTF-B to complement the main-line approach to mirror-fusion reactors. This third MFTE configuration was called the MFTF-B Axicell, and it had a major impact on the vacuum vessel system. The main driver of the vessel changes was the magnet system: several magnets were eliminated, many were added, and all were relocated. We deleted the 4-m-long extensions at each end of the vessel, 
where the two large A-cell magnets had previously resided, and we had to add a new set of vessel legs and a ring stiffener at each end of the central cell to support the four new axicell magnets. Also, because the central-cell solenoid magnets moved from a 2-m spacing to a 1.25-m spacing, we had to relocate all of the central-cell ring stiffeners and legs.

The existence of more magnets along a shorter machine lenfich, tremendously increased the magnetic operating and fault loads. This drore the magnet weights higher because of the need for stronger structural cases; consequently, the vessel gravity and earthquake loads grew proportionately. Additionally, we found that the existing ifTF east-vessel legs and concrete foundations could no longer safely react the higher axicell iongitudinal forces. This required us to shift more of the longitudinal load into the central cell where tre structural supports and foundations were yet to be built. We accomplished this shift of load by reducing the stiffness of the legs of each end vessel and by increasing the stiffness of the center vessel legs.

\section{B. Axloell Redesign Process}

With our design teams in place at both LLNL and PDM, our finite element models developed, and our calculational methods proven, the axicell redesign effort progressed rapidly. We were able to quickly resize the main vessel components (e.g., ring stiffeners, legs, and shell plates) with hand calculations and two-dimensional code runs so that we could use this new geometry for updating the three-dimensional, complete vessel models. In 
addition, the teams immediately concentrated design and modeling effort in regions of the machine that our experience indicated would be overstressed from the new, higher loads.

\section{Three-Dimensional Finite-Element Models}

The two, three-dimensional finite-element models of the vessel were central to the design effort at both PDM and LLNL. This was true even though the two models had quite different purposes. The LLNL team developed the first model to aid spesification writing, to provide advanced estimates of loading on foundations and magnet-support struts, and to serve as a course check on the more-detalled model of PDM. The PDM model was ciesigned to capture three-dimensional effects so that final sizing of vessel parts could be carried out or checked from the load results. This approach using both models worked extremely well for our design teams, and it was particularly valuable when we needed to quickly redesign the vessel to the axicell configuration. For a comprehensive account of the LLNL model, from modeling assumptions to the analysis of the results, see $R=f s .6$ and 8 .

\section{Axicell Vessel Features}

The magnet-support-strut brackets are the connecting links between the magnet-support struts and the vessel circumferential stiffeners. Because of the high loads on the magnets, a great deal of effort went into the design of the magnet-support-strut attachment points on the vessel. We at LLNL requested that PDM develop a design concept that precluded welds in the load path whenever practical; this ensured that the magnets were supported and restrained by fully inspected parent material.

The general design we settled on for the vertical and horizontal brackets was a solld, round bar with a slot machined in each end to form a clevis (Fig. 3). The magnet-attachment end had a single hole bored through 
the bar to accept the pin from the magnet-support strut. The vesse1attachment end had two or three holes bored through the bar so that the bar could be slipped onto the web of a ring stiffener and pinned directly to the web. This meant actually removing a portion of vessel shell plate so that the bracket could be joined directly to the main structural member. A vacuum seal was made later using a sheet metal cup that was welded to the bar and the adjacent shell plate. (At the double ring stiffeners, the vessel end of the bar was pinned to a thick plate that was bolted between the two webs.) There are 56 magnet-attachment-point brackets of this design on the MFTF-B Axicell configuration.

The brackets described above reside in the ring stiffeners and, as such, are designed to react forces only in the transverse plane. To restrain the magnets against the earinguake and magnetic forces operating in the longitudinal direction, PDM evolved a different design concept for these socalled drag-strut brackets. They are each made from two large plates that are joined, but somewhat separated, to form a clevis inside the vessel where they attach to the magnet-support strut. Outside the vessel skin these brackets are attached in yarious ways to the webs of the two adjacent rirg stiffeners and, also, directly to the shell plate. In the center vessel each of these drag strut brackets is in line with the column of longitudinal vessel stiffeners and forms part of that end-to-end column. These drag struts react forces along a line-of-action that is not entirely longitudinal. Therefore, at the vessel surface there is both a radial and longltudinal component of force. The two adjacent $r$ ing stiffeners react the radial component. The longitudinal component is shared by the shell plate and the longitudinal stiffeners. Some of these 16 dragmstrut brackets carry loads as high a 350 tonnes. 
To provide access to the interior, the vessel skin has about 500 penetrations, or ports. Most of these are circular, with cliameters ranging from 5 to $203 \mathrm{~cm}$. All ports, except for the smallest ones and the ones located in very thick shell plate, are reinforced with a washer-shaped doubler plate welded to the vessel skin around the port circumference. A number of penetrations are rectangular in shape, and some are as large as 120 by $210 \mathrm{~cm}$ to allow installation and removal of large pteces of equipment. Many of the largest circular ports carry loads up to three tonnes. Every vessel penetration is sealed with standard O-rings.

\section{CONSTRUCTION OF THE VACUUM VESSEL}

\section{A. Plant and Field Fabrication}

The vacuum-vessel manufacturing process began in early 1982 with the arrival of the Type-304 stainiess steel material at PDM's plant facilities. All vessel components were fabricated at these locations and at several subcontractor sites. Because shop work iends to be more efficient than field work, and therefore more economical, we bullt the subassenblies in the largest possible pieces at these plants and then shipped the pieces by truck or railcar to the construction site at LLNL.

The first step in the fabrication process was to polish the inner surface of all of the shell plate to facilitate cleaning of the finished vacuum vessel. Next, the shell plate and the flanges were rolled to the correct radius. After cutting and preparing edges for welding, the subassembly pieces were fit and welded together. Because most of the major MFTF-B subassemblies are cylinders or cones that are too large in diameter to ship completely assembled, PDM fabricated each of them in three or four sections with the remaining longitudinal seams to be made in the fjeld. Each 
section consisted of the curved shell plate with the matching portions of the ring stiffeners weided on the outer surface. Other fabricated components included 36 vessel legs, 4 neutral-bean domes, 4 midsection plates, about 400 vessel-shell penetrations, 72 magnet-support-strut brackets, 2 center-vesselsupport structures, numerous longitudinal stiffeners, and a multitude of smaller parts.

As the circular sections arrived in Livermore from the PDM plants, they were carefully fit and welded together. We used precise surveying techniques and equipment to ensure that we met the exacting alignment requirements of the final vessel assembly. Additional components, such as magnet-support-strut brackets and penetrations, were welded in place prior to moving each completed cylinder the short distance from the fabrication site to the erection area inside the vault. In this way, PDM assembled two west-end-vessel cylinders, two transition cones, two transition cylinders, and six central-cell modules. B. Assembly in the Vault

Inside the vault, LLNL built the reinforced concrete foundations to which the vacuum vessel support structures were secured. The west vessel foundation is geometrically similar to the east vessel one, except that it is more highly reinforced to be significantly stronger. This îundation consists of four piers directly attached to a thick, underlying concrete mat. Embedded in the top of each pier are two adjustable base plates to which the vessel legs are welded. The central-cell foundations are two separate, reinforced mats, each with mounting plates for center-vessel support-structure attachment. We split the central-cell foundations because there is a large buttress or shear wall across the lower, center vault; this buttress stabilizes the 23-m-high side walls. 
The erection sequence developed by PDM meshed with our demanding and changing project schedule at LLNL. (The PDM teams were constrained in their planning by the 55-tonne capacity of the vault bridge crane.) Their work inside the vault began by setting the west-end-vessel legs in place and welding them to the steel base plates on the piers. Next, the two, 10.6-mdiameter west-vessel orlinders were mounted on the legs. These two cylinders were joined with four, equally spaced, curved plates called midsections, which already had longitudinal stiffeners welded on to them. Then, the four neutral-beam domes were welded between the two cylinders at the vessel top, bottom, and both sides. All of these erection operations required carerul fitting and measurement to meet LLNL's criterion for centerline alignment of the vessel within a 5-cm-diameter circle over the entire vessel length. Next, PDM erected the east and west transition cores. These cones provide the geometry for changing from the larger end vessels to the $8-\mathrm{m}^{--}$ diameter central cell. These cones are welded directly to the inboard portion of the end-vessel cylinders. The center-vessel support structures were then assembled and welded to the foundation base plates. This allowed the 28 center-vessel legs to be bolted on the stainless-steel box beams. The last welded structures, the east and west transition cyinndera, coulu now be installed. They were welded to the transition cones at one end and the outermost set of center-vessel legs on the other.

The last vacuum vessel structures that we erected were the six removable center-vessel modules. Each of these cylinders, in turn, from the east to the west, was fit in place, carefully aligned, and welded to its legs. When the modules were in final position, PDM measured the local gap at each of the 624 flange bolts in the first 6 joints. Custom shim blocks were then machined for installation at final assembly time. The last joint, with 128 shims, was left 
unmeasured until final assembly so that slight adjustments could be made. These six modules were then moved to the magnet assembly yard for installation of the central-cell solenoid magnets.

\section{v. ACCEPTANCE TESTING OF THE VACUUM VESSEL}

\section{A. Vacuum Integrity}

As part of our final acceptance tests, we had PDM perform a vacuum leak test on each of the elght sections of the vessel. To do this, PDM designed and fabricated three, spherlcally-shaped, carbon-steel test heads. These heads are $8 \mathrm{~m}$ in diameter and fit all of the modules and both transition cylinders. On completing the field fabrication of each module, PDM mounted two of the test heads and checked the vacuum integrity of that individual module. With the third test head and an end dome, leak checks were run on each of the completed end vessels. Later, we conducted the first pumpdown of the completed vacuum vessel with high confidence because we had followed this procedure arit, consequently, had tested everything but the seven welded intermodule vacuum-seal bands.

\section{B. Geometric Integrity}

The extensive acceptance test procedure for the vacuum vessel included the verification of every important dimension on the finished vessel. Features that were checked by PDM and LLNL were the vessel centerline alignment, the location of each magnet-support-strut bracket, the location of all ports, the aiming of certain critical ports, and the location of numerous mounting pads and brackets. This data is being combined to form a two volume acceptance test report. Additionally, PDM produced a complete set of as-buflt 
drawings. With the vacuum leak test information and the material certifications, this package forms a comprehensive record of the existing vacuum vessel.

\section{vI. PREPARATION FOR THE INTECRATED ENGINEERING TESTS}

\section{A. Magnet Installation and Center Vessel Reassembly}

The Tandem Mirror Fusion Test Facility was a line item in the Congressional budget and is scheduled for completion in June of 1986, although LLNL plans to accomplish all milestones by December 1985. Our last tasks for this project are assembling the machine and then conducting a series of engineering tesis to verify that the operational requirements of the system are met. We have salled this test series the Integrated Engineering Tests. Assembly of the machine started in December of 1984 with installation of the magnets into the vacuum vessel and reassembly of the center vessel modules. There are a number of variations in the order in which these tasks could be performed, but we were constrained by the availability of the new magnets for the axiceli configuration. First, the yin-yang magnets were moved into their respective end vessels through the open, outboard ends. Next, the transition magnets were installed witr the building crane lifting them into the central-cell region and moving them out,kard through their transition cylinders into the end vessels. These transition magnets were followed, in the same manner, by the axicell magnets.

With the above work completed, the center-vessel modules could be reinstalled. Remember, they had been transported to the magnet assembly yard where two solenoid magnets were hung in each module. The trip back to the vault was made on a special low-bed traller. The building crane then lifted each module over the west vessel and placed it on the center-vessel support 
structure. Shim blocks and bolts were installed in each gap, and the module legs were bolted to the center-vessel-support-structure box beams. With all modules reinstalled, the seven vacuum-seal bands were welded in place. This completed the vacuum-tight, welded envelope that ran from end dome to end dome.

\section{B. Vacuum Integrity Testing}

The vacuum integrity requirement for the total vessel system is a helium-gas leak rate or less than $1 \times 10^{-6}$ Torr $\ell / s$. To demonstrate this level of performance, we began the first pumpdown of the entire MFTF-B vacuum vessel on October 1, 1985. This was also the beginning of the Integrated Engineering Test series. Currently, in mid-October 1985, we are systematically checking each of the 500 penetrations, 7 center-vessel vacuumseal bands, and 2 end-dome seals. Our procedure is to introduce hellum into a plastic bag that is taped over the 1 tem, or part of the 1 tem, and read the response on a calibrated mass spectrometer connected to the vessel interior. The leak rates for every feature will then be summed to verify the total leak rate of the vessel.

A view of the entire MFTF-B vacuum vessel with ilis external components in place is shown in Fig. 4. This photo was taken about a month before the Integrated Engineering Tests began.

\section{ACGNOWLEDGENT}

This work was performed under the auspices of the U.S. Department of Energy by the Lawrence Livermore National Laboratory under contract number W-7405-ENG-48. 


\section{REFERENCES}

1. J. W. GERICH, Design and Construction of the Vacuum Vessel for the Tandem Mirror Fusion Test Facility, in Proc. of the 9th International Vacuum Conference, Madrid, Spain, September 25-0ctober 1, 1983, UCRE -88964 (1983).

2. P. J. FLEMING AND W. C. CHRONIS, Deg1gn Features of the Vacuum Veggel and Cryopumping System for MFTF-B Axicell, in Proc. of the 10th IEEE Symposium on Engineering Problems of Fusion Research, Philadelphia, PA, December 5-9, 1983.

3. S. J. SACKETT, Ugers Manual for SAP4, Lawrence LI vermore National Laboratory, Livermore, CA, UCID-18226 (May 1979).

4. H. J. WEAVER, D. B. McCALLEN, AND M. W. ELI, Dynamic Testing of the MFTF Containment Vessel Structural System, Lawrence Livermore National Laboratory, Livermore, CA, UCRL -53307 (1982).

5. V. N. KARPENKO AND D. S. NG, Application of Structural-Mechanics Methods to the Design of Large Tandem-Mirror Fusion Devices (MFTE-B), in Proc. of the $8 \mathrm{th}$ International Jonference on Structural Mechanics in Reactor Technology, Brussels, Belgium, August 19-23, 1985.

6. D. S. NG, Static and Dynamic Analyses on the MFTF-B Vacuum Vessel, in Proc. of the 10th IEEE Symposium on Engineering Problems of Fusion Research, Philadelphia, PA, December 5-9, 1983.

7. O. R. MASLENIKOV, L. W. TIONG, AND J. J. JOHNSON, Seismic Analyges for the Mirror Fusion Test Facility: Soll-Structure-Interaction Analyses of the Vessel, Structural Mechanics Associates, San Ramon, CA (1984).

8. D. S. NG, The Final Report of Static and Dynamic Analyses on the MFTF-B Vacuum Vessel System, Lawrence Livermore National Laboratory, LIvermore, CA, UCRL $-53690(1985)$. 
FIGURE CAPTIONS

Fig. 1. Artist's drawing of the MFTF-B machine, its surrounding concrete vault, and the building in which it is located.

Fig. 2. Elevation view of MFTF-B with the east end of the vessel cut away showing the vacuum vessel shape and the location of the magnets. Note the end vessels are supported on large concrete piers: and the center vessel is supported by a cross-braced steel structure.

Fig. 3. Sketch showing the general design of the vertical and horizontal magnet-support-strut brackets that eliminate welds in the direct load path. The stainless-steel bars run from 13 to $22 \mathrm{~cm}$ in diameter. They actually pass through the vessel shell, thus transferring loads directly to the main structural members through the web pins.

Fig. 4. View of the top of the MFTF-B machine on September 26, 1985. The auxiliary equipment installed on the vacuum vessel obscures its main features, but indicates the complexity involved in assembling this machine. The large tanks in the left foreground are LHe Dewars that feed the cryopanels and magnets. Most, of the pipes visible are cryogenic fluid-transfer lines or vacuum-pumping lines. 
J. W. Gerich - Figure 1

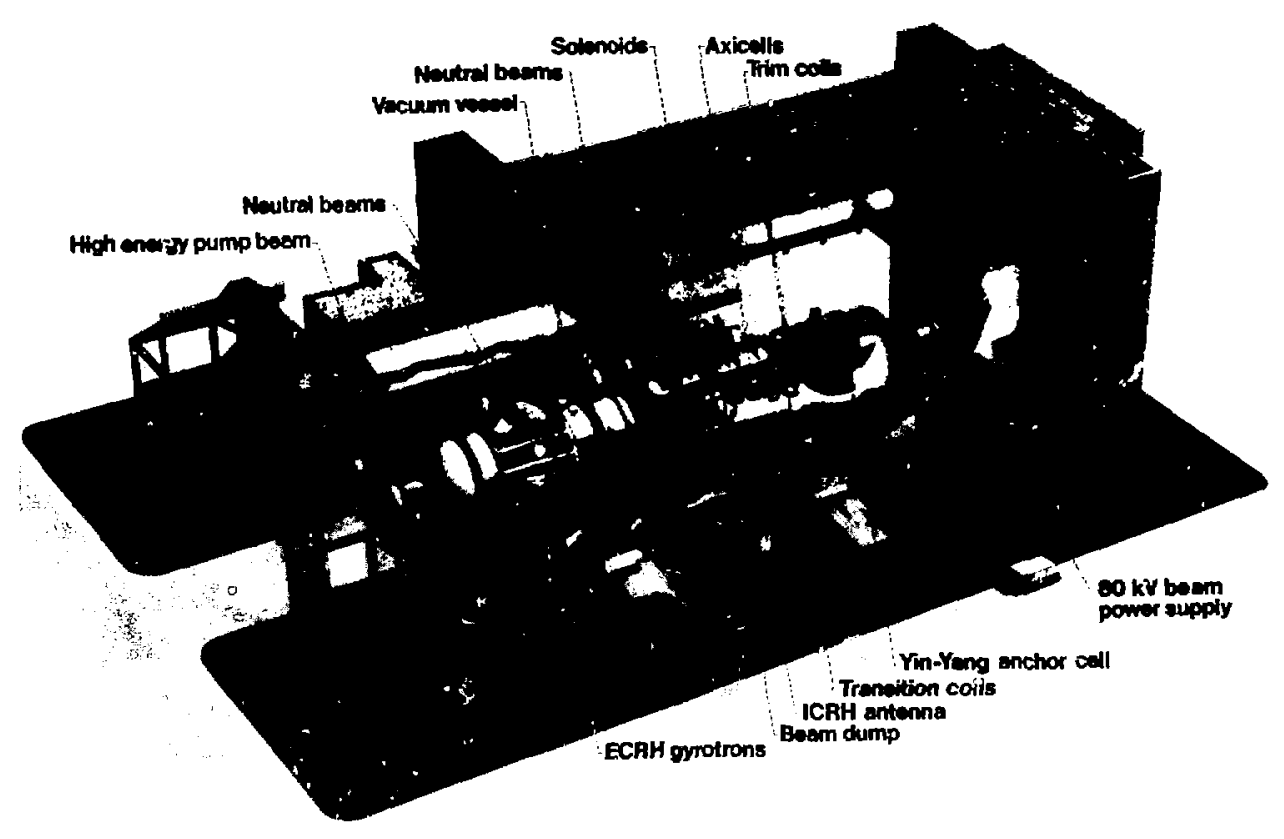


J. W. Gerich - Figure 2

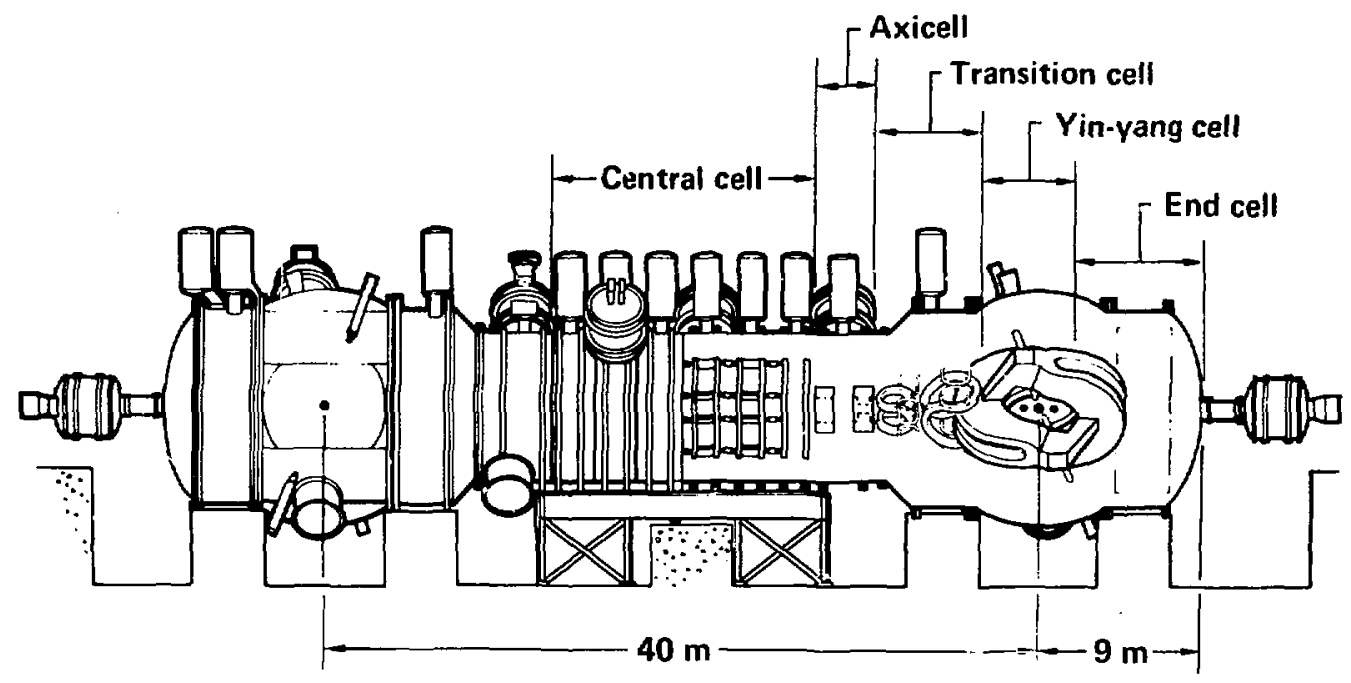


J. W. Gerich - Figure 3

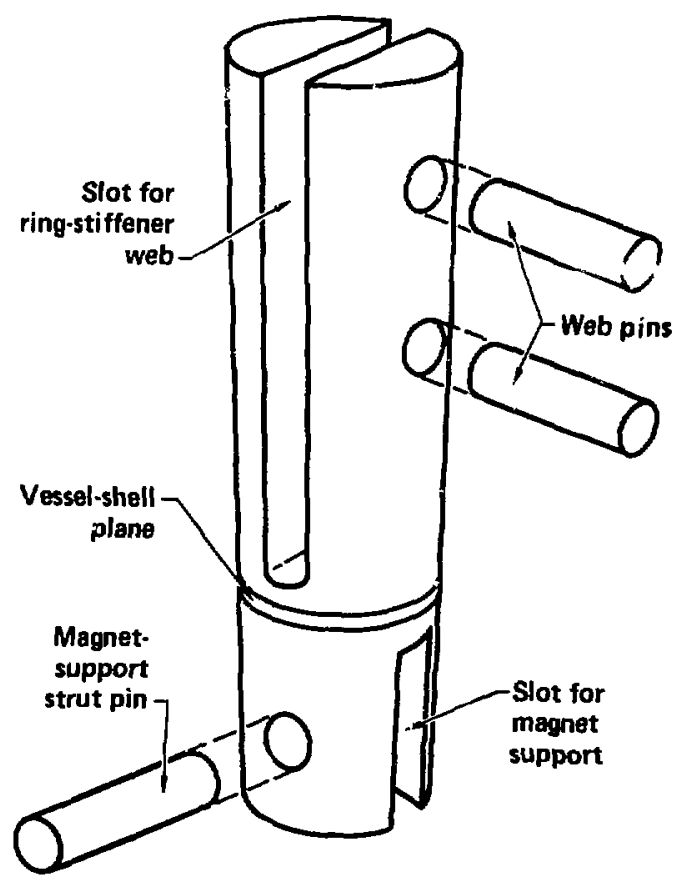




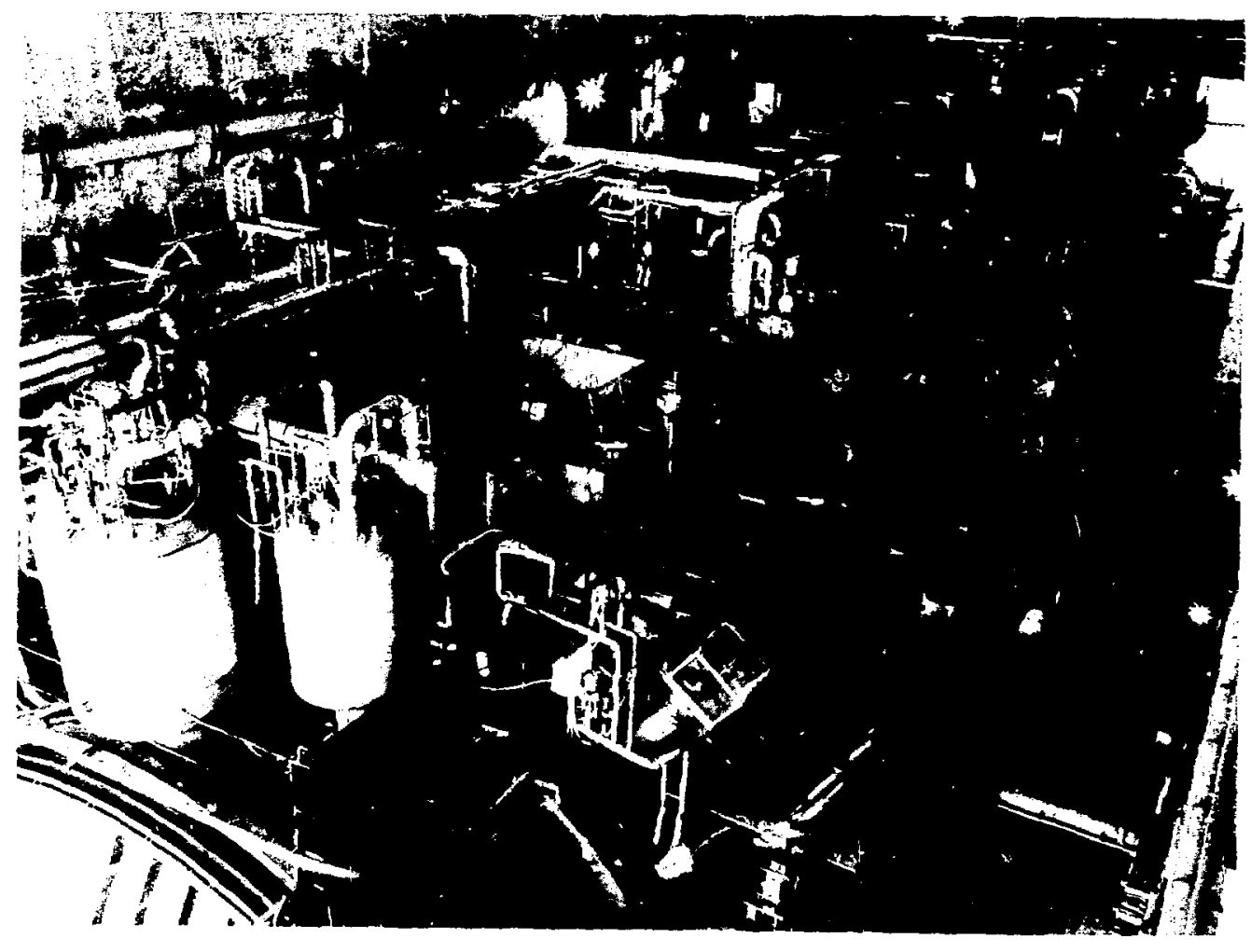

\section{DISCLAMER}

This report was prepared as an account of work sponsored by an agency of the United States Government. Neither the United States Government nor any agency thereof, nor any of their employes, makes any warranty, express or implied, or assumes any legal liability or responsibility for the accuracy, completeness, or usefulness of any information, apparatus, product, or process disclosed, or represents that its use would not infringe privately owned rigbts. Reference berein to any specific commercial product, process, or service by trade name, trademark, manufacturer, or otherwise does not necessarily copstitute or imply its endorsentent, recommendation, or favoring by the United States Government or any agency thereof. The views and opinions of authors expressed herein do not secessarily state or reflect those of the United States Government or any agency thereof. 